\title{
Proceso de integración de las jóvenes vascas de ascendencia africana
}

The integration process of the basque young women

of african ancestry

\author{
Irune Ruiz Ciarreta, Oier Ochoa de Aspuru Gulin, \\ Maite Fouassier Zamalloa • Irune.ruiz@ehu.eus \\ IKUSPEGI-OBSERVATORIO VASCO DE INMIGRACIÓN/ \\ IMMIGRAZIOAREN EUSKAL BEHATOKIA
}

Recibido: 04/10/2019

Aceptado: 14/11/2019

\section{RESUMEN}

En este artículo se presentan parte de los resultados de una investigación elaborada por Ikuspegi-Observatorio Vasco de Inmigración acerca del proceso de integración de las jóvenes de segunda generación de ascendencia africana en la Comunidad Autónoma de Euskadi. Para la consecución de dicho estudio se ha llevado a cabo una investigación de corte cualitativo basado en la realización de tres grupos de discusión con mujeres jóvenes de ascendencia magrebí y subsahariana. El estudio evidencia las dificultades a las que estas jóvenes se han venido enfrentando en sus procesos de aculturación en una sociedad que, a pesar de haber crecido en ella, las continúa viendo como extranjeras.

Palabras clave: Inmigración, segunda generación, aculturación.

\section{ABSTRACT}

This article presents some of the key findings of the research conducted by Ikuspegi-Basque Observatory of Immigration on the integration process of the young second generation women of african ancestry in the Basque Autonomous Region. In order to accomplish this objective, this research followed a qualitative approach with three focus groups where women of both north-African and sub-Saharan ancestry took part. This study shows the difficulties these young women have faced over their acculturation processes within a society that, although they were raised in it, keeps seeing them as foreigners.

Keywords: Immigration, second generation, acculturation.

\section{INTRODUCCIÓN}

Desde que se iniciara el proceso migratorio durante las últimas décadas del siglo xx y principios del xxi, la sociedad vasca se ha venido transformando en una sociedad con una mayor diversidad tal y como nos vienen indicando los últimos datos publicados por el Instituto Nacional de Estadística (INE). Dentro de esta diversidad es necesario hablar de las 
denominadas segundas generaciones, hijos e hijas de personas llegadas del extranjero que han nacido y crecido en Euskadi y que representan la diversidad que viene adoptando nuestra sociedad.

El presente artículo se enmarca dentro de un estudio más amplio realizado por IkuspegiObservatorio Vasco de Inmigración, «LA DIVERSIDAD INFANTIL Y JUVENIL EN LA CAE: las (mal) llamadas segundas generaciones». Este estudio ha sido financiado parcialmente por el Gobierno Vasco y ha permitido acercarse por primera vez a la realidad de los hijos e hijas de las personas inmigrantes de origen extranjero en Euskadi, así como a la de sus familias y a la de las personas que se relacionan con estas en su día a día.

En el contexto concreto de las jóvenes de ascendencia africana, se plantearon una serie de preguntas de investigación las cuales vinieron guiando el trabajo realizado:

— ¿Cuáles consideran las mujeres de ascendencia africana que son los principales aspectos que condicionan su integración en la sociedad vasca?

— ¿Cuáles son en sus palabras las principales áreas de exclusión de la mujer de ascendencia africana?

—¿Qué expectativas de futuro tienen estas mujeres?

En este marco, y partiendo de estas preguntas el objetivo principal fue analizar el proceso de integración y de construcción de la identidad de las mujeres jóvenes de ascendencia africana, bien de ascendencia magrebí, bien de ascendencia subsahariana, residentes en la Comunidad Autónoma de Euskadi (CAE en adelante).

En concreto, nos interesamos por estas mujeres debido a que a la luz de diferentes estudios se trata de un colectivo en un grave riesgo de vulnerabilidad. Por una parte, estudios como el informe «Mujeres inmigrantes extranjeras en la CAE» elaborado por Aierdi y Oleaga (2011) para Emakunde o el «Estudio Diagnóstico sobre el fenómeno migratorio 2014» realizado por Ikuspegi-Observatorio Vasco de Inmigración (2014) para el Ayuntamiento de Vitoria-Gasteiz dejan patente el riesgo de estancamiento y de potencial exclusión que sufre este colectivo por, entre otros factores, el desconocimiento de las lenguas oficiales, el color de su piel o algunos aspectos religiosos. Por otra parte, el «Barómetro: Percepciones y actitudes hacia la población de origen extranjero» realizado de manera anual por Ikuspegi (2018) atestigua así mismo el grado de simpatía que siente la población vasca hacia dichas procedencias, siendo precisamente la población de origen magrebí la que de forma sistemática peor valora la ciudadanía vasca.

Este artículo recoge parte de los resultados obtenidos en tres grupos de discusión realizados, uno en Gipuzkoa y dos en Bizkaia. Así, cada grupo estuvo compuesto por mujeres entre 16 y 25 años de origen o ascendencia magrebí y del África subsahariana. Esta técnica permitió recoger información de tipo actitudinal, comportamental y proyectiva, fundamentalmente ahondando en los porqués de las cosas. 
Respecto a cómo se organiza este artículo, está dividido en cuatro apartados. Primeramente presentamos un breve marco teórico acerca de las segundas generaciones y su proceso de integración y aculturación. Posteriormente, realizamos un acercamiento al colectivo de origen africano y de ascendencia africana residente en Euskadi. Hecho el primer acercamiento, el tercer apartado pone el foco en lo recogido en los grupos de discusión y en sus principales resultados. Por último, se presentan las conclusiones y se reflexiona sobre todo lo comentado anteriormente.

\section{MARCO TEÓRICO}

Uno de los principales cambios a largo plazo que han traído los flujos migratorios de las últimas décadas ha sido la aparición de las llamadas segundas generaciones de migrantes en el Estado español (Portes et al., 2013). Por segunda generación se hace referencia a los hijos e hijas de personas de origen extranjero que han nacido y crecido en un hogar inmigrante independientemente de que hayan nacido en el país de origen de sus progenitores (Alba y Holdaway, 2013). No obstante, este continúa siendo un término discutido y polémico en tanto que homogeneiza al colectivo y consiente su estigmatización al remarcar su ascendencia extranjera sobre cualquier otra característica (Fullaondo, 2017).

Desde Ikuspegi-Observatorio Vasco de Inmigración se propone la siguiente tipología de cara a poder captar la diversidad interna que caracteriza a este colectivo de segunda generación —Cuadro 1-. Así, la segunda generación (2.0) estaría formada por las personas nacidas o reagrupadas con cuatro años o menos y con al menos un progenitor de origen extranjero. Las personas reagrupadas entre los cinco y los once años pero que han comenzado sus procesos de socialización en el país de origen dan lugar a la categoría 1.5. Finalmente, los hijos e hijas de personas inmigrantes que llegaron a la CAE con 12-15 años (1.25) o más de 16 años (1.0) serían prácticamente personas migrantes en primera persona.

Cuadro 1. Tipología Ikuspegi sobre segundas generaciones y características

\begin{tabular}{|l|l|}
\hline \multicolumn{1}{|c|}{ Tipología Ikuspegi } & \multicolumn{1}{c|}{ Colectivo } \\
\hline Segunda generación: 2.0G & Personas nacidas en la CAE o reagrupadas con 4 años o menos \\
\hline Generación mixta: 1.5G & Personas reagrupadas entre 5-11 años \\
\hline Migración en primera persona: 1.25G & Personas reagrupadas entre 12-15 años \\
\hline Migración en primera personas: 1.0G & Personas reagrupadas entre 16-24 años \\
\hline
\end{tabular}

Fuente: Ikuspegi-Observatorio Vasco de Inmigración.

Más allá del debate terminológico, estas nuevas generaciones así como su grado de integración e inclusión resultan clave para el futuro de la sociedad en general (Portes y Rumbaut, 2001), que debe tratar de integrar y educar a sus miembros para convertirlos en una 
parte activa de la misma (Portes et al., 2013). En este sentido, durante los años, se han propuesto numerosos acercamientos y teorías sobre de su proceso de integración y aculturación.

Desde el enfoque culturalista Richard Alba y Victor Nee (2003) describen un proceso por el que, al igual que sucediera con las generaciones anteriores, las minorías llegadas de países extranjeros asimilan y se adaptan sin problemas a las condiciones de la nueva sociedad hasta integrarse y ser absorbidos por la sociedad de acogida (Ibídem). La perspectiva de Alba y Nee ha sido la más utilizada durante años en las ciencias sociales y describe un proceso de integración optimista, afirmando que la movilidad social de las nuevas generaciones hasta la clase media es ascendente, gradual y homogénea (Telles y Ortiz, 2008).

Dentro de este enfoque culturalista, pero con una visión de la integración marcadamente más negativa, el autor norteamericano Samuel Huntington habla sobre el reto hispánico y sus efectos en los Estados Unidos (2009). De acuerdo a este, la persistencia de los flujos migratorios de México al país del norte (y el consiguiente aumento de la población mexicana en el país) es un obstáculo para el proceso de aculturación de las nuevas generaciones. Y es que, con el aumento de la población «chicana» esta deja de verse como minoría que debiera de adoptar la cultura del grupo dominante, lo que eventualmente acaba derivando en tensiones entre ambos grupos (ibídem).

La otra gran perspectiva sobre la aculturación de las segundas generaciones es el enfoque estructuralista, donde destaca la teoría de la «asimilación segmentada». De acuerdo a esta teoría, lo fundamental no es tanto si las nuevas generaciones se van a integrar en la sociedad sino en qué estratos de la misma lo van a hacer (Portes et al., 2006). Así, la meta de los progenitores es que sus hijos e hijas se integren y alcancen un estilo de vida de clase media, pero no todos y todas pueden acceder a esa posibilidad (ibídem). Esta viene marcada por elementos como el capital humano de los progenitores, la estructura o composición familiar y el entorno en el que se integran (ibídem).

Otro elemento que cobra importancia dentro del debate sobre el proceso de integración de las nuevas generaciones es el de la construcción de la identidad personal. En este sentido, Terrén (2011) nos recuerda que aquí también han surgido dos perspectivas diferenciadas. Por una parte, el modelo lineal o straight-line model basado en las experiencias de los primeros migrantes europeos en Estados Unidos. De acuerdo a este, a medida que pasa el tiempo y aumenta la exposición a la cultura dominante del lugar, entre las segundas generaciones se da una disolución de los elementos simbólicos y culturales que forman parte de la identidad de la primera generación (ibídem). En este sentido, se parte de la idea de que con el paso del tiempo los y las descendientes de esas primeras generaciones mostrarán una progresiva identificación hacia el país de destino y su cultura.

Por otra parte, desde la perspectiva transnacionalista se ha venido criticando ese modelo lineal, mostrando que este no necesariamente se cumple y que, por el contrario, familias 
de origen extranjero pueden desarrollar procesos de integración positivos sin necesariamente renunciar a la identidad y cultura de sus países o comunidades étnicas (ibídem), dando lugar a identidades mixtas o múltiples.

Más allá de estas perspectivas teóricas, han sido numerosos los trabajos que han venido poniendo de manifiesto así mismo el efecto que la actitud de las sociedades de destino tiene en la identificación de las segundas generaciones con una u otra cultura. Los estereotipos y los comentarios negativos ralentizan el proceso de integración de las segundas generaciones, reafirmando entre estas la identificación con la cultura de origen de sus progenitores (Portes y Rumbaut, 2001; Louie, 2006).

\section{EL COLECTIVO AFRICANO EN CIFRAS}

Como hemos señalado, el objetivo de este artículo es conocer el proceso de integración de las segundas generaciones, y más concretamente de las hijas de personas de ascendencia africana residentes en la CAE. Este apartado tiene por objetivo realizar un primer acercamiento al colectivo de origen africano y de ascendencia africana en Euskadi, de cara a tener una primera imagen del colectivo antes de entrar a analizar su proceso de integración y aculturación.

\subsection{Colectivo de origen africano en la CAE}

De acuerdo a los datos del Padrón Continuo - Tabla 1-, a 1 de enero de 2018 la población de origen africano en la CAE era de 44.716 personas, lo que suponía un $21,7 \%$ de la población total de origen extranjero. Por áreas de origen, el Magreb era la principal procedencia de las personas de origen africano residentes en la CAE - 28.867 personas a 1 de enero de 2018 - a gran distancia de África subsahariana -15.849 personas-. Por países de procedencia, Marruecos era el principal país con 22.717 personas, lo que suponía un 78,7\% y un 64,6\% del total de la población magrebí y africana respectivamente. Tras este, Argelia -5.128 personas-, Senegal -4.618 personas - y Nigeria -3.443 personas - eran los principales orígenes. Así, entre estas cuatro procedencias suponían un 80,3\% del total de la población de origen africano residente en la comunidad autónoma.

Si analizamos la población de origen africano atendiendo al sexo —Gráfico 1-, en 2018 había unas 16.717 mujeres de origen africano viviendo en Euskadi. En comparación a los hombres, bien en el caso de África en general, bien entre los principales países de origen las mujeres tienen un peso porcentual notoriamente inferior al de los hombres. Así, un $62,6 \%$ del total de las personas de origen africano residentes en la CAE eran hombres, con porcentajes similares en el caso de Marruecos — 61,7\% - y Argelia —61,7\%—, pero que aumentan notoriamente en el caso de Senegal - 82,9\%-. 
Tabla 1. Población de origen africano residente en la CAE por área de origen y principales nacionalidades. 2018

\begin{tabular}{|l|c|c|}
\hline & $\begin{array}{c}\text { N } \\
\text { (absolutos) }\end{array}$ & $\begin{array}{c}\text { \% respecto } \\
\text { al Total África }\end{array}$ \\
\hline Magreb & 28.867 & 64,6 \\
\hline Marruecos & 22.717 & 50,8 \\
\hline Argelia & 5.128 & 11,5 \\
\hline África Subsahariana & 15.849 & 35,4 \\
\hline Senegal & 4.618 & 10,3 \\
\hline Nigeria & 3.443 & 7,7 \\
\hline Total África & $\mathbf{4 4 . 7 1 6}$ & $\mathbf{1 0 0 , 0}$ \\
\hline
\end{tabular}

Fuente: elaboración propia a partir de los datos del Padrón Continuo.

Gráfico 1. Distribución por sexo de la población de origen extranjero, de origen africano y de los principales países de procedencia (\%). 2018

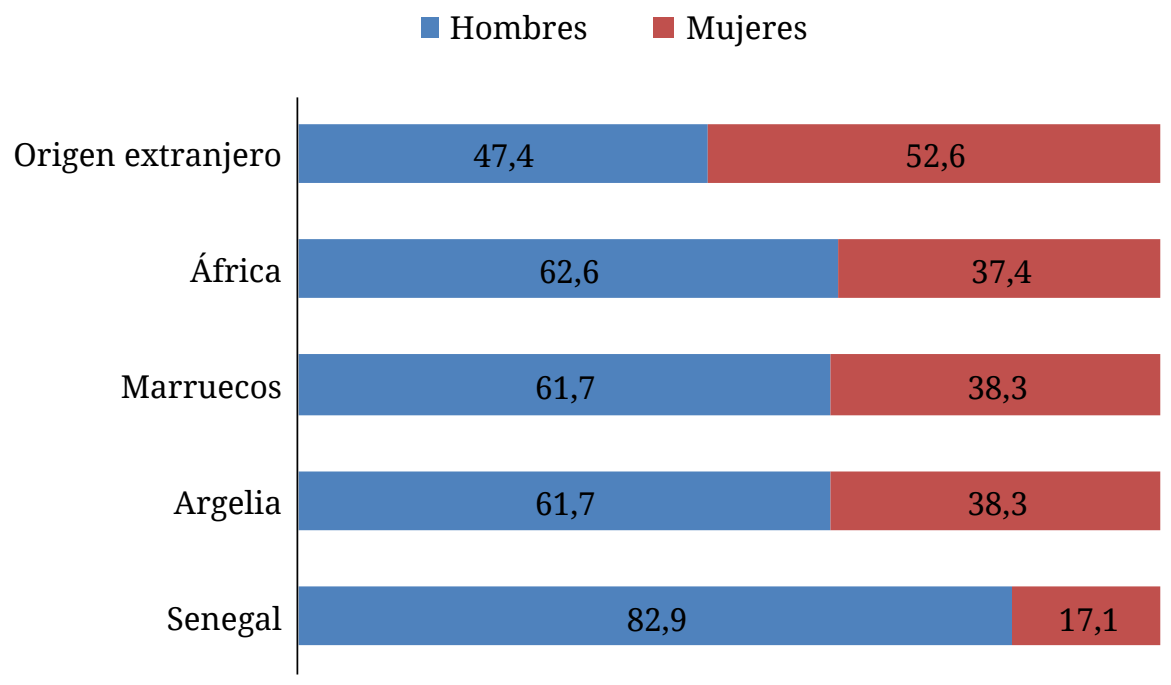

Fuente: elaboración propia a partir de los datos del Padrón Continuo.

Así mismo, de acuerdo al últimos datos de la EPIE de 2014 — Gráfico 2-, la tasa de paro de la población de origen africano era significativamente más elevada que las del resto de procedencias. Concretamente, el $62,5 \%$ en el caso de las personas de origen senegalés, el 68,4\% entre las personas procedentes de Magreb y un 81,2\% en el caso del resto de países africanos. Esta además se vio acrecentada con respecto a los datos del año 2010 como consecuencia de la recesión económica.

De esta forma, las personas de origen africano constituyen en la actualidad el grupo con mayores cuotas de vulnerabilidad. Si a esto además se le añade que las mujeres suponen un grupo reducido dentro de un colectivo con un importante riesgo de vulnerabilidad de 
serie, el hecho de centrar el análisis en el caso de las mujeres de ascendencia extranjera está sobradamente justificado.

\section{Gráfico 2. Tasa de paro de la población originaria de Ma- greb, Senegal y resto de África (\%). 2010/2014}

- 2010 - 2014

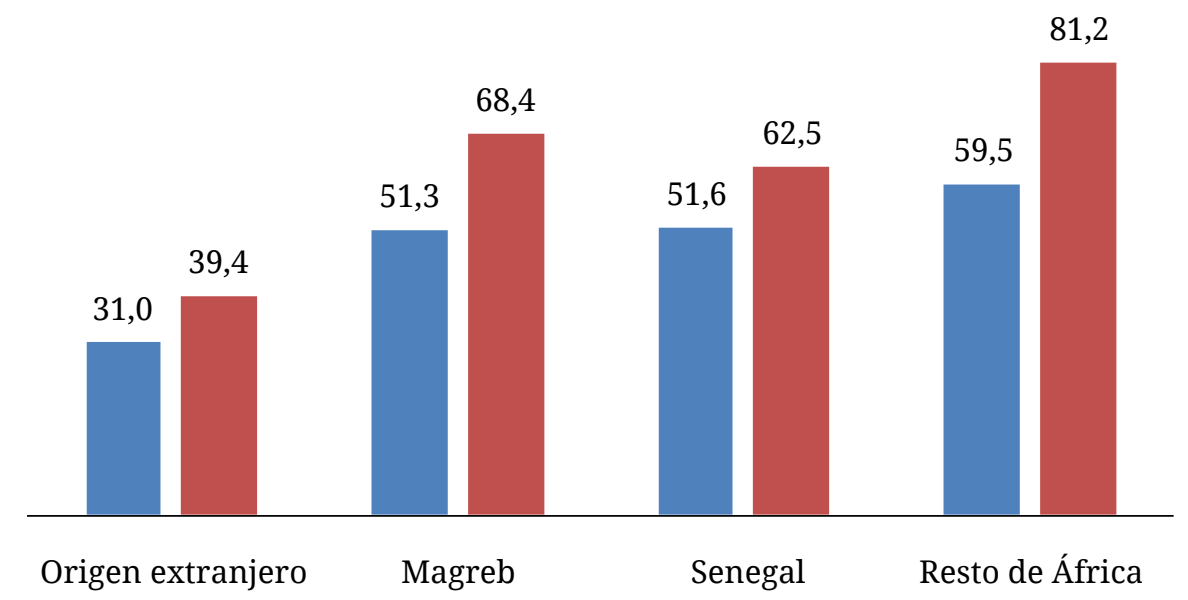

Fuente: Autoría propia a partir de los datos de la Encuesta de Población Inmigrante Extranjera de 2014.

\subsection{Personas de ascendencia africana en la CAE}

En lo que respecta a las llamadas segundas generaciones - Tabla 2-, el estudio de Otero y Mendoza (2017) a partir de los datos del INE muestra cómo en 2011 había unas 76.914 personas de entre 0 y 24 años de ascendencia extranjera residiendo en la CAE, de las cuales 6.459 tenían nacionalidad marroquí, mientras que otras 1.386 tenían nacionalidad argelina. En este sentido, y en cierto modo reafirmando el peso significativamente menor que tienen las personas de ascendencia subsahariana dentro del colectivo de ascendencia africana, en los datos del Censo de Población y Vivienda se observa cómo más allá de estas dos nacionalidades del norte de África en 2011 no había ninguna otra nacionalidad africana entre las más numerosas entre las personas de ascendencia extranjera.

En lo que se refiere de forma estricta al colectivo de segunda generación, volviendo a la tipología propuesta por Ikuspegi ${ }^{1}$, por la que este grupo estaría formado por aquellas personas nacidas en la CAE o reagrupadas con menos de 4 años, algo más de la mitad —-55,6\%de las 6.459 personas entre 0 y 24 años de ascendencia y con nacionalidad magrebí habrían nacido dentro del territorio nacional, y algo más pero en un porcentaje todavía cercano — 58,7\% - en el caso de los y las jóvenes de ascendencia argelina.

\footnotetext{
${ }^{1}$ El estudio realizado por Otero y Mendoza (2017) forma parte del estudio sobre las segundas generaciones elaborado por Ikuspegi - Observatorio Vasco de Inmigración. En la medida en que esto es así los datos de dicho informe siguen la tipología que se presentaba con anterioridad dentro del apartado teórico.
} 
Proceso de integración de las jóvenes vascas de ascendencia africana | I. Ruiz, O. Ochoa de Aspuru, M. Fouassier

Tabla 2. Jóvenes de entre 0 y 24 años de ascendencia extranjera por principales nacionalidades. 2011

\begin{tabular}{|l|r|r|r|r|r|}
\hline & $\mathbf{2 . 0 G}$ & $\mathbf{1 . 5 G}$ & $\mathbf{1 . 2 5 G}$ & $\mathbf{1 . 0 G}$ & TOTAL \\
\hline Española & $\mathbf{9 3 , 3}$ & 4,6 & 1,3 & 0,7 & 32.827 \\
\hline Marroquí & 55,6 & 12,9 & 13,1 & 18,4 & 6.459 \\
\hline Rumana & 30,1 & 30,6 & 13,3 & 26,0 & 5.819 \\
\hline Colombiana & 12,7 & 39,4 & 22,2 & 25,6 & 4.468 \\
\hline Boliviana & 22,9 & 40,5 & 16,2 & 20,4 & 3.911 \\
\hline Ecuatoriana & 24,5 & 30,3 & 20,2 & 25,2 & 3.137 \\
\hline Argelina & 58,7 & 18,3 & 6,8 & 16,2 & 1.386 \\
\hline Portuguesa & 66,3 & 14,4 & 7,2 & 12,1 & 1.337 \\
\hline Brasileña & 21,8 & 40,7 & 17,0 & 20,5 & 1.264 \\
\hline Paraguaya & 5,2 & 26,8 & 8,3 & 59,7 & 1.212 \\
\hline Peruana & 21,0 & 42,3 & 14,9 & 21,8 & 1.142 \\
\hline Chilena & 19,1 & 48,1 & 21,8 & 11,1 & 803 \\
\hline Dominicana & 26,0 & 33,3 & 21,3 & 17,3 & 781 \\
\hline China & 42,4 & 33,0 & 5,2 & 19,3 & 615 \\
\hline Nicaragüense & 19,6 & 19,1 & 8,7 & 52,6 & 530 \\
\hline Pakistaní & 39,0 & 18,6 & 20,3 & 22,2 & 636 \\
\hline Resto & 48,7 & 22,1 & 11,0 & 18,3 & 10.587 \\
\hline Total & $\mathbf{6 0 , 6}$ & $\mathbf{1 7 , 7}$ & $\mathbf{8 , 7}$ & $\mathbf{1 3 , 0}$ & $\mathbf{7 6 . 9 1 4}$ \\
\hline
\end{tabular}

Fuente: Otero y Mendoza (2017) a partir del Censo de Población y Viviendas de 2011.

Junto a los datos por nacionalidades los datos del Censo de Población y Viviendas muestran también el número de personas de ascendencia extranjera por país de nacimiento - Tabla 3-. En lo que se refiere a los países africanos, sólo Marruecos (3.638) y Argelia (779) aparecen entre los principales países de nacimiento de las personas de ascendencia extranjera. Si cruzamos y comparamos los datos por nacionalidad y por país de nacimiento resulta significativa la diferencia en el número de personas en un lado y en el otro. Concretamente, el número de personas de ascendencia extranjera con nacionalidad extranjera es superior a las nacidas en dichos países.

Nuevamente en lo que se refiere a las segundas generaciones de forma estricta, bien en el caso de Marruecos (22,6\%) bien en el caso de Argelia (22,1\%) el peso porcentual que estas tenían dentro del grupo de jóvenes que habían nacido en el extranjero es significativamente menor al que ocupan si atendemos a los datos de nacionalidad. Así, esto indica que una parte destacada de las mismas han nacido en territorio nacional frente a las que han nacido en el extranjero y han sido reagrupadas con 4 años o menos. 
Tabla 3. Jóvenes de entre 0 y 24 años de ascendencia extranjera por país de nacimiento. 2011

\begin{tabular}{|l|r|r|r|r|r|}
\hline & $\mathbf{2 . 0 G}$ & $\mathbf{1 . 5 G}$ & $\mathbf{1 . 2 5 G}$ & $\mathbf{1 . 0 G}$ & TOTAL \\
\hline Estado español & $\mathbf{9 8 , 5}$ & 1,2 & 0,2 & 0,2 & 40.161 \\
\hline Rumanía & $\mathbf{1 5 , 9}$ & 36,4 & 16,0 & 31,8 & 4.831 \\
\hline Colombia & $\mathbf{8 , 4}$ & 42,5 & 24,0 & 25,1 & 4.681 \\
\hline Marruecos & 22,6 & 20,8 & 23,8 & 32,7 & 3.638 \\
\hline Bolivia & 15,3 & 44,4 & 17,8 & 22,4 & 3.562 \\
\hline Ecuador & 13,2 & 37,9 & 22,6 & 26,3 & 3.197 \\
\hline Perú & 21,3 & 39,4 & 15,8 & 23,5 & 1.226 \\
\hline Brasil & 12,2 & 44,4 & 20,6 & 22,8 & 1.201 \\
\hline Paraguay & 4,2 & 24,4 & 7,3 & 64,1 & 1.130 \\
\hline Portugal & 50,8 & 24,6 & 10,0 & 14,6 & 957 \\
\hline Argelia & 22,1 & 39,0 & 12,1 & 26,8 & 779 \\
\hline Chile & 18,5 & 48,5 & 23,1 & 9,9 & 758 \\
\hline República Dominicana & 13,6 & 42,2 & 26,3 & 17,9 & 756 \\
\hline Argentina & 30,5 & 30,9 & 25,8 & 12,9 & 699 \\
\hline Venezuela & 36,9 & 38,1 & 6,1 & 18,9 & 561 \\
\hline Cuba & 10,8 & 33,7 & 26,7 & 28,8 & 520 \\
\hline Pakistán & 25,1 & 22,8 & 24,9 & 27,2 & 518 \\
\hline Resto & 27,6 & 33,6 & 12,2 & 26,5 & 7.733 \\
\hline Total & $\mathbf{6 0 , 6}$ & $\mathbf{1 7 , 7}$ & $\mathbf{8 , 7}$ & $\mathbf{1 3 , 0}$ & $\mathbf{7 6 . 9 0 8}$ \\
\hline
\end{tabular}

Fuente: Otero y Mendoza (2017) a partir del Censo de Población y Viviendas de 2011.

Así mismo, las segundas generaciones están, por definición, formadas por hijos e hijas de personas de ascendencia extranjera. La tabla 4 muestra la nacionalidad de los y las progenitores de la juventud de segunda generación residente en la CAE. Según se observa, de forma general, en 2011 una parte significativa de estos habían obtenido la nacionalidad y eran por tanto ciudadanos y ciudadanas españolas.

Con respecto a la ascendencia de las segundas generaciones africanas, una parte destacable de los y las progenitores magrebíes todavía mantenían la nacionalidad de sus países de origen (4.228 personas), al igual que sucediera en el caso de los progenitores de origen subsahariano (1.980 personas). Así mismo, vemos en los datos como la proporción por sexos que se observa en los datos a nivel general se mantiene también entre los progenitores de estas segundas generaciones, siendo los hombres $(59,6 \%)$ mayoría frente a las mujeres $(40,4 \%)$. 
Proceso de integración de las jóvenes vascas de ascendencia africana | I. Ruiz, O. Ochoa de Aspuru, M. Fouassier

Tabla 4. Jóvenes de entre 0 y 24 años de ascendencia extranjera nacidos en el Estado español y con nacionalidad española: nacionalidad de los padres y madres. 2011

\begin{tabular}{|l|r|r|r|r|}
\hline \multirow{2}{*}{} & \multicolumn{2}{|c|}{ Padre } & \multicolumn{2}{c|}{ Madre } \\
\cline { 2 - 5 } & $\mathbf{N}$ & $\%$ & 11.696 & 39,4 \\
\hline Estado español & 10.779 & 36,3 & 10.529 & 35,4 \\
\hline Latinoamérica & 7.833 & 26,4 & 3.151 & 10,6 \\
\hline Magreb & 5.510 & 18,5 & 1.670 & 5,6 \\
\hline Resto de África & 2.558 & 8,6 & 836 & 2,8 \\
\hline Bulgaria y Rumanía & 1.144 & 3,9 & 450 & 1,5 \\
\hline Resto UE & 611 & 2,1 & 516 & 1,7 \\
\hline América del Norte & 405 & 1,4 & 191 & 0,6 \\
\hline Resto de Asia & 327 & 1,1 & 292 & 1,0 \\
\hline Oceanía & 260 & 0,9 & 87 & 0,3 \\
\hline Ampliación UE25 & 105 & 0,4 & 180 & 0,6 \\
\hline China & 100 & 0,3 & 73 & 0,2 \\
\hline Perdidos & 73 & 0,2 & 32 & 0,1 \\
\hline Total & 0 & 0,0 & $\mathbf{2 9 . 7 0 4}$ & $\mathbf{1 0 0 , 0}$ \\
\hline
\end{tabular}

Fuente: Otero y Mendoza (2017) a partir del Censo de Población y Viviendas de 2011.

\section{LAS JÓVENES DE ASCENDENCIA AFRICANA EN LA CAE}

El acercamiento cualitativo realizado por Ikuspegi-Observatorio Vasco de Inmigración sobre el colectivo de mujeres vascas de ascendencia africana (magrebíes y subsaharianas) nos permite ilustrar de primera mano los discursos, vivencias, experiencias y expectativas de estas jóvenes en distintos ámbitos. Cabe destacar que los grupos de mujeres tuvieron las siguientes características:

-Grupo 1: Mujeres de ascendencia magrebí y subsahariana de entre 20 y 22 años residentes en Bilbao.

- Grupo 2: Mujeres de ascendencia magrebí y subsahariana de entre 17 y 21 años residentes en Bilbao.

- Grupo 3: Mujeres de ascendencia magrebí y subsahariana de entre 19 y 24 años residentes en Gipuzkoa.

En concreto en este apartado vamos a centrarnos en cuatro aspectos clave de sus procesos de integración como son: La identidad y el proceso de construcción de la misma, la importancia de la familia y su red social, la evaluación que hacen las jóvenes de ascendencia africana de la convivencia en Euskadi y, por último, sus expectativas respecto al futuro. 
No obstante, cabe destacar que para profundizar en el tema es aconsejable acudir al informe original elaborado por Ikuspegi-Observatorio Vasco de Inmigración «Las vascas de ascendencia africana: presente y futuro» dentro del proyecto LA DIVERSIDAD INFANTIL Y JUVENIL EN LA CAE: Las (mal) llamadas segundas generaciones.

\subsection{La identidad}

En el caso del proceso de construcción de identidades, cabe destacar que se trata de un tema transversal en todos los ámbitos analizados con las mujeres. Todos los apartados tratados en los grupos de discusión (familia, red social, educación, ámbito laboral, etc.) contienen elementos asociados a la identidad y por tanto referencias a la misma. Esto es debido principalmente a la importancia otorgada en los discursos de las jóvenes a la cultura y la religión. Tanto la cultura como la religión conforman su persona y condicionan todos los aspectos de su vida y por tanto, su identidad como mujeres de segunda generación.

Preguntadas por su sentimiento de pertenencia, bien hacia la cultura vasca, bien hacia la cultura de sus progenitores, en la mayoría de casos se detecta una crisis a la hora de identificar un territorio con el que identificarse en concreto. Es decir, estamos ante un colectivo que no se percibe a sí mismo como extranjero, pero que por el contrario tampoco se siente exclusivamente vasco.

"Yo siempre decía que soy del mar. Entre Ceuta y Algeciras, de ahí. Con los delfines. Porque en todos los sitios te dicen que eres de fuera. Yo me he quedado en el Estrecho.» (Grupo 2)

«La verdad es que yo no me siento ni de aquí ni de allí ni de ningún lado. Es una pregunta que siempre me han hecho. No me siento española, no me siento vasca, no siento euskalduna, por esa manera de decir. Tampoco me siento marroquí ni árabe. Lo único que podría ser capaz de decir es que me siento musulmana.» (Grupo 2)

Se observan en los discursos de las jóvenes los casos que la perspectiva transnacionalista ha venido describiendo, es decir, el de jóvenes que se han socializado en la comunidad y han convivido desde siempre con la cultura vasca, pero al mismo tiempo, han nacido en un hogar con una cultura y tradiciones propias. Esto ha hecho que desarrollen identidades mixtas, a medio camino entre ambas culturas, pero que precisamente por esa dualidad que describimos viven este hecho con cierta incertidumbre. Y es en ese contexto que cobra importancia el sentimiento religioso.

Así pues las referencias a su religión son variadas, unas se muestran más practicantes que otras pero en general dicen sentirse más libres en este aspecto que las personas que han nacido y crecido en los países de origen de sus familiares. Cabe destacar la madurez y consciencia que tienen sobre las diferencias religiosas que viven respecto al resto de personas jóvenes vascas de su edad, como por ejemplo: el consumo de alcohol. En el caso de 
la religión musulmana, admiten que en la sociedad el principal foco se centra en el uso del pañuelo. Perciben un desconocimiento generalizado sobre su significado y una consecuente discriminación hacia las usuarias.

"¿Sabes lo que pasa? Que muchas veces confunden la religión con el origen, con la nacionalidad. Cuando yo digo que soy musulmana, me preguntan si soy árabe.» (Grupo 3)

«Mezclan también un poco religión con nuestra cultura.» (Grupo 1)

En relación a esto, las mujeres nos trasladan también las dudas que perciben por parte de la sociedad vasca, principalmente debido a que su color de piel, fenotipo o símbolos religiosos no son de la creencia mayoritaria, lo cual genera sentimientos como el rechazo y la no aceptación. Mientras que por una parte de la sociedad reciben un apoyo que favorece su integración, hablan de cómo siempre hay otra parte de la sociedad que trata de obstaculizarlas en este proceso. En este sentido resulta curioso escuchar a estas jóvenes vascas hablar en estos términos, haciendo alusión al término «integración» en repetidas ocasiones.

"Yo creo que siempre va a haber un sector que va a querer que te integres y que ayuda a que te integres. Pero va a haber otro sector que siempre te va a poner pegas y que va a hacer todo lo posible para que tú no avances, para que el de aquí avance. Punto.» (Grupo 1)

En definitiva, del discurso de las mujeres sobre este tema se desprende que la sociedad vasca todavía tiene un importante camino por recorrer. Por una parte, las mujeres de ascendencia extranjera han venido atestiguando mediante sus vivencias el hecho de que aun habiendo crecido y socializado en Euskadi una parte de la población todavía no las considera vascas y obstaculiza sus esfuerzos por integrarse. Por otra parte, y aquí sí de forma más general, las mujeres describen el desconocimiento de la sociedad vasca hacia algunos elementos y la necesidad de que conozca sus orígenes y diferencie mejor qué es cultura y qué es religión.

\subsection{La familia y red social}

Las participantes transmiten de manera clara que la familia es la institución más importante en sus vidas. Casi la totalidad viven aún en casa con la familia y es por ello también, que la esfera privada adquiere especial protagonismo en sus vidas, siendo «la vida en el hogar» su principal centro de reunión con familiares y amistades y el espacio donde especialmente mantienen su cultura y religión.

Por tanto, mantienen en su discurso que los lazos familiares son el pilar de sus vidas. Saben que sus progenitores tomaron la decisión de empezar una nueva vida de manera estratégica en familia para brindarles mayores oportunidades laborales y educativas. Por 
todo ello, la vida familiar es muy importante para todos, siendo su principal vínculo en la CAE.

«Son un apoyo para conseguir mis metas, Si no hubiera tenido el apoyo de mi familia, no hubiera podido realizar unos estudios.» (Grupo 2)

Perciben que la importancia de la cultura de origen a la hora de educarlas ha dado continuidad a los roles de género instaurados en los países de origen de sus progenitores. Es por ello que mantienen aún el rol de «cuidadoras y realizadoras de labores domésticas» adquirido desde la niñez, liberando a los varones del hogar de esas tareas.

«En mi país se considera más al hombre que a la mujer. Mi hermano tiene 24 años y en las cuestiones de limpieza y así, se escaquea. No es el trabajo del hombre. Es un poco machista y encima mi madre le apoya. Dice que ese es el trabajo de la mujer. Mi madre sigue con esas costumbres.» (Grupo 2)

En lo que a la red social se refiere, hay quienes mantienen relación con «cuadrillas» autóctonas, pero la gran mayoría se relacionan en su día a día con mujeres de su mismo origen y ascendencia africana. Esto se debe principalmente a que se sienten más cómodas y comprendidas en el aspecto cultural y religioso.

\subsection{La convivencia}

De manera generalizada, las mujeres participantes consideran que la convivencia es buena, pese a existir ocasiones en que son tratadas como "extranjeras» cuando ellas mismas no se sienten como tal. Admiten como en el espacio público, en el ámbito laboral y en el educacional aún viven rodeadas de prejuicios y estereotipos, principalmente ligados a un fenotipo diferente y a unas creencias religiosas distintas. Una vez más, esto destaca especialmente entre las mujeres que practican la religión musulmana y utilizan velo. Aunque aparentemente en los últimos años se hayan superado algunos estereotipos y barreras, a día de hoy, permanecen las diferencias, los comentarios inadecuados y las miradas desconfiadas.

«Pero a mí me ha pasado que he ido al (comercio) y pedirte el NIE, cosas de esas ¿por qué me tienes que tomar por extranjera?» (Grupo 2)

«Y aunque tengas amigas, siempre serás la negrita de clase, mi amiga la negra o mi amiga la mora. Siempre lo mismo, de hijos a padres. Por muy integrado que estés o por mucho euskera que sepas.» (Grupo 1)

En su opinión, «la integración» para la sociedad vasca descansa sobre un asimilacionismo cultural, es decir, para ser una "verdadera vasca» deben dejar de lado su cultura, religión y costumbres, para pasar a formar parte de lo que ellos consideran «la mayoría». Como viéramos en el marco teórico, en el caso del proceso de aculturación de las segundas gene- 
raciones este asimilacionismo cultural ha tomado forma del denominado enfoque culturalista. Este enfoque mantiene que con el paso del tiempo las nuevas generaciones van asimilando la cultura dominante hasta dejar de lado la cultura de origen de sus progenitores. Sin embargo, en los discursos de las mujeres se percibe una oposición hacia este modelo, en tanto que tratan de mantener parte de la cultura y religión de su origen. Aún y todo muchas mujeres dicen sentirse «aceptadas» dentro de su entorno, al menos por una parte de la sociedad.

«Para muchos integrarse es que te quites tus raíces, que dejes tu religión de lado y que te portes como nosotros. Ponte pintura en la cara y ponte blanca.» (Grupo 1)

\subsection{Expectativas de futuro}

Por último, se preguntó a estas chicas por sus expectativas a futuro. En este sentido, sus deseos no se diferencian de las del resto de personas de su edad. Principalmente mencionan el ámbito laboral, desean poder encontrar en un futuro trabajos dignos relacionados con sus estudios y mejorar, en muchos casos, las condiciones precarias y las dificultades vividas en sus familias. Saben que una de las principales razones por las que sus padres y madres migraron a otro país fue para poder ofrecer un futuro mejor a sus hijos e hijas.

No obstante, más allá del deseo la realidad es otra, comentan que no les está resultando fácil el acceso al mercado de trabajo. Nuevamente admiten que estas dificultades derivan principalmente de su aspecto físico y su fenotipo, que sigue generando controversia entre las personas empleadoras y afloran estereotipos negativos muy fuertes y grotescos, tanto a la hora de buscar empleo como una vez en él.

«Por teléfono están interesados en ti y te dicen que se soluciona con una entrevista. Y cuando vas, te dicen que tenían otra perspectiva, otro perfil. Te cierran las puertas de golpe cuando ya tenías una ilusión Por lo que te habían dicho por teléfono. Y de repente te encuentras con todo lo contrario.» (Grupo 2)

Otra de las intenciones a futuro más destacadas es la de ser madres y formar una familia. Las mujeres desean que sus hijos e hijas puedan integrarse más que ellas en la sociedad y que puedan optar a ser como cualquier joven de su edad, con las mismas preocupaciones y las mismas oportunidades.

«Yo no te sabría decir. En el sentido de sociedad, esperemos que lo tengan más fácil que nosotras. Aunque tendrá que avanzar bastante. Pero en el sentido de la educación en casa y ese tipo de cosas, lo veo muy, muy, muy difícil.» (Grupo 1)

«De aquí a veinte años, cuando mis hijos estén haciendo la carrera, que puedan optar a un trabajo de verano como opta cualquier otro joven de aquí. Que sean igual que ellos. Espero que un poco sí.» (Grupo 2) 
En relación a la educación que les darían a sus hijos e hijas una de las cosas a las que aluden es a que les gustaría darles una educación en igualdad de género, y es que son plenamente conscientes de que a lo largo de su infancia y juventud han sido tratadas de manera desigual por su género y no quieren inculcar esta discriminación a sus futuros hijos e hijas. Pese a sus deseos, no tienen la convicción de que sus descendientes superarán totalmente el hecho de vivir entre dos culturas y presienten que tampoco tendrán un futuro fácil.

«No sé cómo sería. Esperemos que no sea como me han educado a mí mis padres. Les voy a enseñar que tiene que hacer las cosas de casa también. Porque no quiero que sea como mis hermanos, que no hacían nada. Quiero que haga algo.» (Grupo 1)

Todo esto, es resultado de vivir en un contexto de diversidad sin elaborar. Esto indica, una vez más, que en el imaginario de la sociedad aún no se reconoce plenamente la existencia de personas que forman parte de la sociedad vasca desde nacimiento o muy corta edad, que están creciendo y desarrollándose aquí como personas, aun teniendo un color de piel distinto o practicando una religión no mayoritaria.

\section{CONCLUSIONES}

A la luz de los últimos datos hemos visto cómo la población de origen africano supone en la actualidad un 24,7\% del total de las personas de origen extranjero residentes en la Comunidad Autónoma de Euskadi. En lo que respecta a las personas de segunda generación, en 2011 había unas 6.459 personas entre 0 y 24 años de ascendencia marroquí residiendo en la comunidad, y otras 1.386 de ascendencia argelina.

Más allá de lo que indican los datos, a través de sus vivencias las jóvenes de ascendencia africana nos han transmitido las dificultades y preocupaciones a las que se enfrentan en una sociedad vasca que, en mayor o menor medida, espera de ellas una integración culturalista. Esto es, que abandonen la cultura y la religión del país de origen de sus progenitores y adopten en su lugar la cultura vasca.

Precisamente, en sus experiencias vitales han podido coincidir con personas que, a pesar de haberse criado en Euskadi y que ellas mismas no se ven como extranjeras, no las acaban de considerar «autóctonas». Mencionan que sus rasgos, fenotipo y religión las distingue de "la mayoría» y que ello las ha hecho tener que recibir comentarios negativos en ocasiones. En este sentido, comentan que esto se troca especialmente problemático en el ámbito laboral, donde los estereotipos entre las personas empleadores todavía resultan recurrentes.

De esta forma, las experiencias que las jóvenes de ascendencia africana han venido teniendo no distan mucho de los testimonios recogidos en trabajos anteriores por autores como Portes y Rumbaut (2001) o Louie (2006). De acuerdo a estos autores los comentarios 
estereotipados de los que son blanco las personas de ascendencia extranjera no hacen sino ralentizar el proceso de integración de las segundas generaciones. Por lo que hemos podido comprobar en la actualidad las mujeres de ascendencia extranjera no parecen compartir esta tesis en tanto que por lo general se sienten más o menos integradas, aunque todavía está por ver qué desarrollo pueda tener esto de cara al futuro.

En esta misma línea, son jóvenes que han crecido entre dos mundos, entre la cultura de sus hogares y la cultura vasca. Esto hace que tengan dificultades para definir su identidad, sin que sientan que ni una ni otra categoría les representa, todo lo contrario. Vemos así lo que Terren (2011) bautizaba como identidades mixtas o múltiples, donde tienen una integración positiva dentro de la sociedad pero siguen manteniendo los lazos con la identidad y la cultura de la primera generación. En el caso que nos ocupa, su identidad está caracterizada de forma notoria por su religión, en la mayoría de los casos, el Islam.

Respecto al futuro hablan en su mayoría de tener hijos e hijas y de tener una familia. Y así se sienten esperanzadas con que las generaciones futuras puedan crecer en una sociedad que no las vea (y trate) como extranjeras, y a título personal que puedan darles una educación igualitaria sin las diferencias por género que ellas han tenido que sufrir.

En este sentido, y a modo de sugerencia, del discurso se desprenden recomendaciones en torno al aprendizaje y sensibilización en materia de diversidad cultural y religiosa. Siendo estos considerados como uno de los pilares básicos para la consecución de una Euskadi más diversa e intercultural.

\section{REFERENCIAS BIBLIOGRÁFICAS}

Aierdi Urraza, X. \& Oleaga Páramo, J. A. (2011). Estudio sobre las mujeres inmigrantes extranjeras de la sociedad vasca. Vitoria-Gasteiz: Emakunde.

Alba, R., \& Holdaway, J. (2013). "The Children of Immigrants at School. A Comparative Look at Integration in the United States and Western Europe». New York: New York University Press.

Alba, R., \& Nee, V. (2003). Remaking the American main stream. Assimilation and contemporary immigration. Cambridge: Harvard University Press.

Fullaondo Elordui-Zapaterietxe, A. (2017). Un acercamiento teórico y conceptual. Bilbao: Servicio Editorial de la Universidad del País Vasco.

Huntington, S. P. (2009) The Hispanic Challenge. Foreing Policy, 141. Recuperado de: https://foreignpolicy.com/2009/10/28/the-hispanic-challenge/ 
Ikuspegi. (2014). Estudio-Diagnóstico sobre el fenómeno migratorio en Vitoria-Gasteiz. Recuperado de: https://www.vitoria-gasteiz.org/docs/wb021/contenidosEstaticos/ adjuntos/es/27/34/62734.pdf

Ikuspegi. (2018). Barómetro: Percepciones y actitudes hacia la población de origen extranjero. Recuperado de: http://www.ikuspegi.eus/documentos/barometros/2018/bar_ CAE_2018_CAS_web.pdf

Louie, V. (2006). Second-generation pessimism and optimism: How Chinese and Dominicans understand education and mobility through ethnic and transnational orientations. International Migration Review, 40(3), 537-572.

Otero Gutiérrez, B., \& Mendoza Pérez, K. (2017). La diversidad infantil y juvenil de la CAE en cifras. Bilbao: Servicio Editorial de la Universidad del País Vasco.

Portes, A., Kelly, P. F., \& Haller, W. (2006). La asimilación segmentada sobre el terreno: la nueva segunda generación al inicio de la vida adulta. Migraciones. Publicación del Instituto Universitario de Estudios sobre Migraciones, (19), 7-58.

Portes, A., \& Rumbaut, R. (2001). Legacies: the story of the immigrant second generation. Berkeley: University of California Press.

Portes, A., Vickstrom, E., \& Aparicio Gómez, R. (2013). Hacerse adulto en España. Autoidentificación, creencias y autoestima de los hijos de inmigrantes. Papers: revista de sociologia, 98(2), 0227-261.

Telles, E., \& Ortiz, V. (2008). Generations of exclusion: Mexican-Americans, assimilation, and race. New York: Russell Sage.

Terrén, E. (2011). Identidades desterritorializadas. El sentimiento de pertenencia nacional entre los adolescentes de familias inmigradas. Papers. Revista de Sociologia, 96(1), 97-116. 